\title{
AGROMETEOROLOGIA
}

\section{AVALIAÇÕES FENOLÓGICAS E AGRONÔMICAS EM CAFÉ ARÁBICA CULTIVADO A PLENO SOL E CONSORCIADO COM BANANA 'PRATA ANÃ' ( ${ }^{1}$ )}

\author{
JOSÉ RICARDO MACEDO PEZZOPANE $\left({ }^{2 *}\right)$; MÁRIO JOSÉ PEDRO JÚNIOR $(3,5)$;PAULO BOLLER GALLO $\left({ }^{4}\right)$; \\ MARCELO BENTO PAES DE CARMARGO $\left({ }^{3,5}\right)$; LUIZ CARLOS FAZUOLI $\left({ }^{3,5}\right)$
}

\begin{abstract}
RESUMO
O trabalho foi realizado em cafeeiros (Coffea arabica L.) cv. Icatu Vermelho IAC 4045, cultivados a pleno sol e consorciados com banana 'Prata Anã' (Musa AAB), em Mococa (SP), em Latitude 21 $28^{\circ}$ S, Longitude $47^{\circ} 01^{\prime} \mathrm{W}$, altitude $665 \mathrm{~m}$. Entre julho de 2001 e junho de 2004 foi acompanhado o desenvolvimento fenológico dos cultivos, além de se avaliar, o crescimento das plantas em altura e diâmetro da copa. Nas safras de 2002, 2003 e 2004 foram avaliados os parâmetros de produção nos dois sistemas de cultivo, além de sua variabilidade nas parcelas do cultivo consorciado. Nos sistemas de cultivo avaliados, o crescimento vegetativo em altura e diâmetro foi maior no período primavera-verão em relação ao período outonoinverno, não tendo sido encontradas diferenças significativas das taxas de crescimento, de desenvolvimento fenológico e dos índices de produção entre os cultivos. No cultivo consorciado, no ponto próximo às bananeiras observaram-se diferenças em relação aos demais pontos amostrados no crescimento vegetativo e desenvolvimento fenológico para algumas épocas do ano, além de apresentar menor produção por planta.
\end{abstract}

Palavras-chave: Coffea arabica, fenologia, crescimento vegetativo, arborização.

\author{
ABSTRACT \\ PHENOLOGICAL AND AGRONOMIC EVALUATIONS IN A COFFEE CROP GROWN \\ UNDER UNSHADED AND SHADED BY 'PRATA ANÃ' BANANA PLANTS
}

A study was carried out in coffee crop (Coffea arabica L.) cv. Icatu Vermelho IAC 4045, unshade and shaded

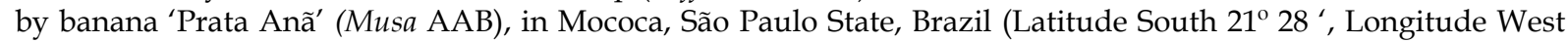
$47^{\circ} 01^{\prime}$, altitude $665 \mathrm{~m}$ ). Phenological data for the coffee crops were taken, from July, 2001 to June, 2004 . The growth of the plants concerning height and diameter was also evaluated. The harvests of 2002, 2003 and, 2004 were appraised by the production parameters, and their variability for different positions in shaded coffee crop. The vegetative growth in height and diameter showed higher activity during the spring-summer period in relation to the autumn-winter period, in both in the cultivation systems evaluated. No significant differences of the growth taxes, of phenological development and of the yield indexes were found. In coffee crop shaded, the nearest point to the banana plants showed differences in relation to the other amostral points in vegetative growth and phenological development for some seasons of the year, besides showing smaller plant yield.

Key words: Coffea arabica, phenology, crop growth, shading

\section{INTRODUÇÃO}

(1) Extraído da Tese de Doutorado do primeiro autor apresentada à Escola Superior de Agricultura "Luiz de Queiroz", Piracicaba (SP). Recebido para publicação em 3 de fevereiro de 2006 e aceito em 19 de abril de 2007.

$\left({ }^{2}\right)$ Centro Universitário Norte do Espírito Santo/UFES, Rua Humberto de Almeida Franklin 257, Bairro Universitário, 29933-480 São Mateus (ES). E-mail: josepezzopane@ceunes.ufes.br (*) Autor correspondente.

$\left({ }^{3}\right)$ Instituto Agronômico de Campinas (IAC), Caixa Postal 28, 13001-970 Campinas (SP).

$\left({ }^{4}\right)$ Pólo Regional de Desenvolvimento Tecnológico dos Agronegócios do Nordeste Paulista (DDD/APTA/SAA), CaixaPostal 58, 13730-970 Mococa (SP).

$\left({ }^{5}\right)$ Com Bolsa de Produtividade em Pesquisa do CNPq. 
Sistemas consorciados de cultivo de café, com sombreamento moderado, podem contribuir para a manutenção da sustentabilidade da produção dessa cultura. Em vista das modificações microclimáticas que ocorrem quando diferentes organismos compartilham o mesmo espaço (BEER, 1998), o cultivo consorciado é uma estratégia de proteção da lavoura de café, minimizando os efeitos do ambiente, como ventos fortes, temperaturas elevadas e excessos de radiação (CAmARgo e Pereira, 1994).

Camargo e Pereira (1994), Beer (1998) e DAMATTA (2004) relatam que o uso de arborização do cafezal, com conseqüente diminuição da radiação incidente, atenua o ciclo bienal da produção, além de alterar o desenvolvimento fenológico do café, proporcionando maior período de grãos maduros, permitindo mais tempo para colheita seletiva, o que pode trazer reflexos positivos na qualidade de bebida. Nesse sentido, VAAst et al. (2004) em trabalhos realizados em cafezais arborizados na Costa Rica obtiveram melhor qualidade do produto nesses sistemas.

Cafezais sombreados tendem a produzir menos que os a pleno sol, devido à menor emissão de nós, fator preponderante à produção da cultura (CANNELl, 1976). Em condições climáticas favoráveis para o cultivo de café e com a utilização intensiva de insumos, como irrigação, adubação e defensivos agrícolas, plantios de café a pleno sol, de maneira geral, produzem mais que cultivos arborizados (DaMatтA, 2004). Diante dessa abordagem pode se inferir que quanto mais restrita for a região para a cafeicultura, característica de área com baixas altitudes, solos pobres ou com baixa fertilidade, maiores serão os benefícios obtidos com o uso da arborização (CAMARGo, 1990; MATIELlo et al., 2002).

BEer et al. (1998) relatam ainda que uma vantagem, em termos de produção, o cultivo de cafeeiros a pleno sol em comparação aos cultivos arborizados poderia ser limitada, principalmente em regiões tropicais, a uma ou duas décadas de ciclos produtivos. Após, a degradação ambiental, proporcionada por erosão do solo e resíduos de fertilizantes e pesticidas poderia reduzir a produtividade e/ou a qualidade do ambiente.

Considerando os aspectos anteriormente abordados, aliado à necessidade de informações a respeito da fenologia e produção de cultivos, o presente trabalho teve o objetivo de avaliar o desenvolvimento fenológico e as produções iniciais em cultivo de café a pleno sol e consorciado com banana 'Prata Anã'.

\section{MATERIAL E MÉTODOS}

Foram realizadas medições de crescimento de plantas, desenvolvimento fenológico e índices de produção durante os meses de outubro de 2001 a setembro de 2004, em sistemas de produção de café (Coffea arabica L), em Mococa, SP ( $21^{\circ} 28^{\prime} \mathrm{S}, 47^{\circ} 01^{\prime}$ $\mathrm{W}$, altitude $665 \mathrm{~m})$, região de clima classificado como Cwa, com inverno seco e verão chuvoso, de acordo com a classificação de Köppen e solo classificado como Argissolo Vermelho-Amarelo (Embrapa, 1999). A área experimental foi constituída de cafeeiros, cv. Icatu Vermelho IAC 4045, enxertado sobre cv. Apoatã IAC 2258, implantados em 1999, cultivados em monocultivo e consorciados com banana (Musa spp. $\mathrm{AAB}$ ) 'Prata Anã'. O espaçamento das plantas de café nos dois sistemas de cultivo foi de $4 \times 1 \mathrm{~m}$, e as bananeiras, de $8 \times 8 \mathrm{~m}$, totalizando 156 plantas/ hectare (Figura 1A). Os sistemas de produção constituíam parcelas de $40 \times 40$ metros, em mesma condição topográfica e de orientação de encosta (nordeste), com baixa declividade, em um total de quatro repetições.

O desenvolvimento das culturas de café e banana foi realizada com os tratos culturais, de acordo com as instruções técnicas para a região. Nas bananeiras, ressalta-se a realização da técnica do desbaste $(20 / 12 / 2001,8 / 3 / 2002,10 / 10 / 2002,17 /$ $12 / 2002,22 / 1 / 2003,28 / 4 / 2003$ e $22 / 1 / 2004$ ), que foi feito para favorecer o maior desenvolvimento e produção da planta, eliminando-se os pés que já produziram e o excesso de brotação para as produções seguintes.

Na figura 1 é apresentada a parcela útil utilizada para obtenção da produção do sistema consorciado (Figura 1A) bem como o detalhe de quatro pontos amostrais dentro da parcela (P1, P2, P3 e P4), onde foram realizadas avaliações nos cafeeiros, de crescimento, desenvolvimento fenológico e índices de produção por planta (Figura 1B).

Em plantas selecionadas nas parcelas de monocultivo e cultivo consorciado (P1 a P4), foram realizadas avaliações de altura das plantas e diâmetro da copa no fim de cada estação do ano. A altura foi determinada fazendo-se uso de uma régua topográfica colocada paralelamente ao caule do cafeeiro, medindose desde a superfície do solo até a gema apical do ramo ortotrópico. O diâmetro da copa foi determinado com a régua topográfica colocada transversalmente ao ramo ortotrópico em relação à linha de cafeeiros, medindo-se a maior distância entre o primeiro par de folhas presentes nos ramos plagiotrópicos opostos.

Utilizando-se a escala fenológica desenvolvida por Pezzopane et al. (2003), que considera a identificação 
de 12 estádios fenológicos, principalmente para o período reprodutivo (após o repouso das gemas), as quais foram atribuídos valores numéricos: (0) Gema dormente; (1) Gema entumecida; (2) Abotoado; (3) Florada; (4) Pós-florada (5) Chumbinho; (6) Expansão dos frutos; (7) Grão verde; (8) Verde Cana; (9) Cereja; (10) Passa; (11) Seco, foi realizado o acompanhamento do desenvolvimento fenológico no período compreendido de agosto de 2001 a junho de 2004, nas plantas selecionadas nas parcelas de monocultivo e cultivo consorciado com banana 'Prata Anã' (P1 a P4).

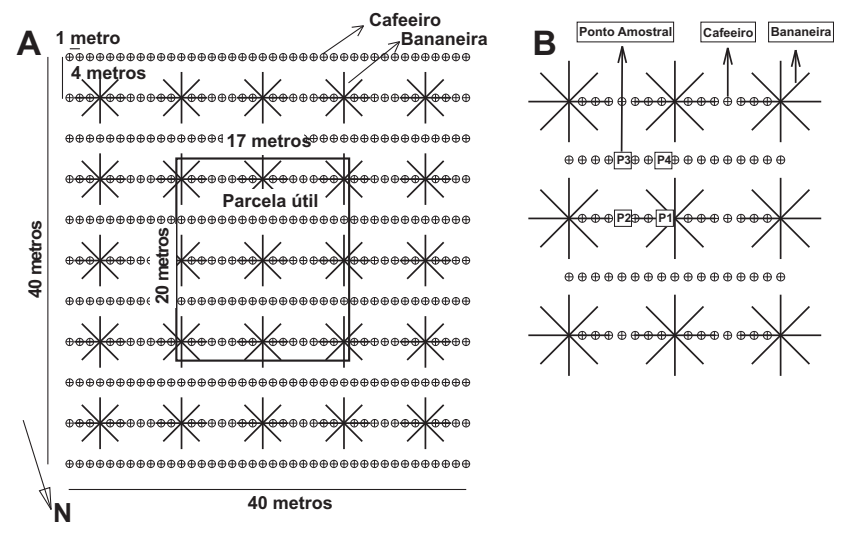

Figura 1. Representação esquemática da parcela consorciada e da parcela útil para fins de avaliação de produção (A) e detalhamento dos pontos amostrais (P1 a P4) de plantas de café dentro da parcela consorciada (B).

Nas plantas selecionadas foi marcado um ramo com orientação norte, no terço médio superior da planta. Em ramos marcados na florada principal, identificada visualmente, foram retiradas todas as flores das floradas subseqüentes. Posteriormente, foram atribuídos valores numéricos relativos ao desenvolvimento fenológico em todos os ramos marcados, em intervalos de 7 a 10 dias, tendo sido considerado o estádio atual de desenvolvimento aquele que tivesse mais de $50 \%$ de ocorrência no ramo.

No fim da safra de 2002, 2003 e 2004, quando as plantas estavam com a maior parte dos frutos nos estádios de maturação cereja e passa, foi realizada a colheita nas parcelas úteis $\left(340 \mathrm{~m}^{2}\right)$ do sistema de produção em monocultivo de café e consorciado com banana 'Prata Anã', em um total de quatro repetições. Na mesma ocasião, foi realizada a colheita nas plantas de café selecionadas nas parcelas de cultivo consorciado com banana 'Prata Anã' (P1 a P4 Figura 1B).

As avaliações de crescimento, desenvolvimento fenológico e índices de produção por planta foram realizadas em oito repetições, sendo para tanto, selecionadas duas plantas ao acaso por ponto amostral (P1 a P4) em cada uma das parcelas do experimento.

Após o procedimento de colheita, as produções permaneceram em secagem natural no terreiro até atingirem o teor de umidade de aproximadamente $11 \%$, tendo sido posteriormente pesadas para a obtenção da produção de café em coco. Além disso, as amostras foram processadas em máquinas de beneficiamento, obtendo-se a massa de café beneficiado. A partir desses dados foi estimado o rendimento (relação entre a massa dos grãos beneficiados e a massa da produção em coco, expressa em porcentagem), que foi utilizado como base para o cálculo de café beneficiado por planta.

Para a caracterização das condições meteorológicas ocorridas durante o período experimental, são apresentados os dados decendiais de temperatura e chuva, além do extrato do balanço hídrico, segundo CAMARGO e CAMARGO (1993), relativo ao período de julho de 2001 a junho de 2004, cujos valores positivos indicam excedentes hídricos e os negativos, deficiência hídrica ou falta de chuva.

O crescimento dos cafeeiros, determinado pela taxa de crescimento em altura e diâmetro das plantas nas avaliações realizadas, foi comparado entre os sistemas de produção, bem como entre os diferentes pontos amostrais do sistema consorciado, com o uso da "análise de intervalos de confiança" (95\%). O mesmo tipo de análise estatística foi utilizada para comparação de produção e rendimento. Para avaliar a variabilidade espacial da produção e rendimento no sistema consorciado, foi realizada a análise de variância e o teste de Tukey, a $5 \%$ de probabilidade para comparação das médias.

\section{RESULTADOS E DISCUSSÃO}

O primeiro ano agrícola do período experimental (2001-2002) representou o início das chuvas em setembro (Figura 2A), com ocorrência de excedentes hídricos a partir de novembro (Figura 2B). Até o início de março de 2002, o período chuvoso foi de elevado excedente hídrico (cerca de $700 \mathrm{~mm}$ ), temperatura amena e alta umidade relativa do ar.

A partir de março de 2002, foi caracterizado um período de deficiência hídrica, cujo período seco perdurou até o fim do mês de outubro de 2002 (Figura 2B), embora tenha sido verificada a ocorrência de chuvas em maio (44 mm), no início e fim de setembro e de outubro (Figura 2A). Em 2002, durante o período de março a outubro, foi totalizado cerca de $420 \mathrm{~mm}$ de deficiência hídrica, em base decendial. 


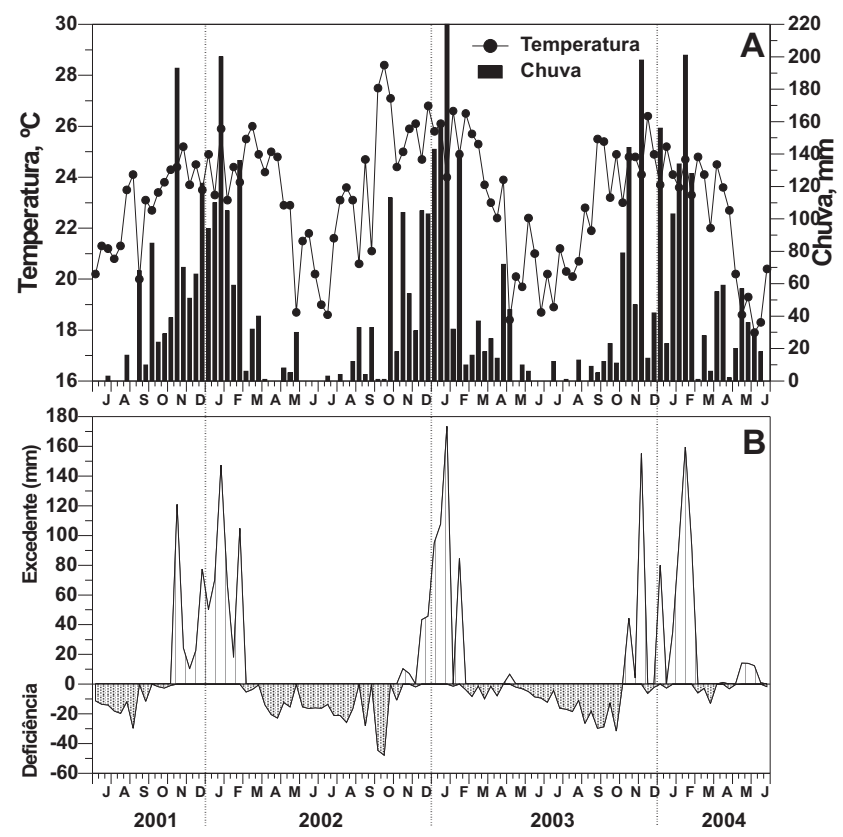

Figura 2. Variação decendial da temperatura média do ar $\left({ }^{\circ} \mathrm{C}\right)$ e da precipitação pluvial $(\mathrm{mm})(\mathrm{A})$ e extrato do balanço hídrico (CAD $=100 \mathrm{~mm}$ ) $(\mathrm{B})$ no período de julho de 2001 a junho de 2004, em Mococa (SP).

No período compreendido de novembro de 2002 e fevereiro de 2003 ocorreu excedente hídrico em torno de $560 \mathrm{~mm}$ (Figura 2B); a partir de março, houve um período de ocorrência de deficiência hídrica, interrompido por ocorrência de chuvas até junho, tendo sido verificado ocorrência de excedentes no início de maio. A partir de junho de 2002, a deficiência hídrica foi constante, totalizando $250 \mathrm{~mm}$ até o fim de outubro (Figura 2B), embora tenham sido verificados pequenas quantidades de chuva a partir de julho. Deve-se ressaltar que o período seco de 2003 foi menos rigoroso que o de 2002.

No fim de 2003, o período de excedentes hídricos perdurou até o início de março de 2004, tendo ocorrido interrupções de ocorrência de chuvas, sendo verificada deficiência hídrica no fim de dezembro. Um ponto a destacar é que, a partir do início de março, quando foram verificados períodos com deficiências hídricas, as chuvas não cessaram, identificando-se em 2004 um outono de característica chuvosa.

\subsection{Crescimento dos cafeeiros}

As taxas de crescimento em altura foram maiores no período primavera-verão em relação ao outono-inverno (Figura 3A); no período de 26/3/2002 a 17/9/2002 ocorreram as menores taxas de crescimento $\left(0,04 \mathrm{~cm} \cdot \mathrm{dia}^{-1}\right.$ no cultivo consorciado e
0,05 cm.dia ${ }^{-1}$ no cultivo a pleno sol), devido à ocorrência de grande período com deficiência hídrica na região de Mococa nesse período (Figura 2B). Variações estacionais do crescimento de cafeeiros com padrões semelhantes nas regiões cafeeiras tradicionais também foram observados por BARROS e MAESTRI (1974), entre outros.

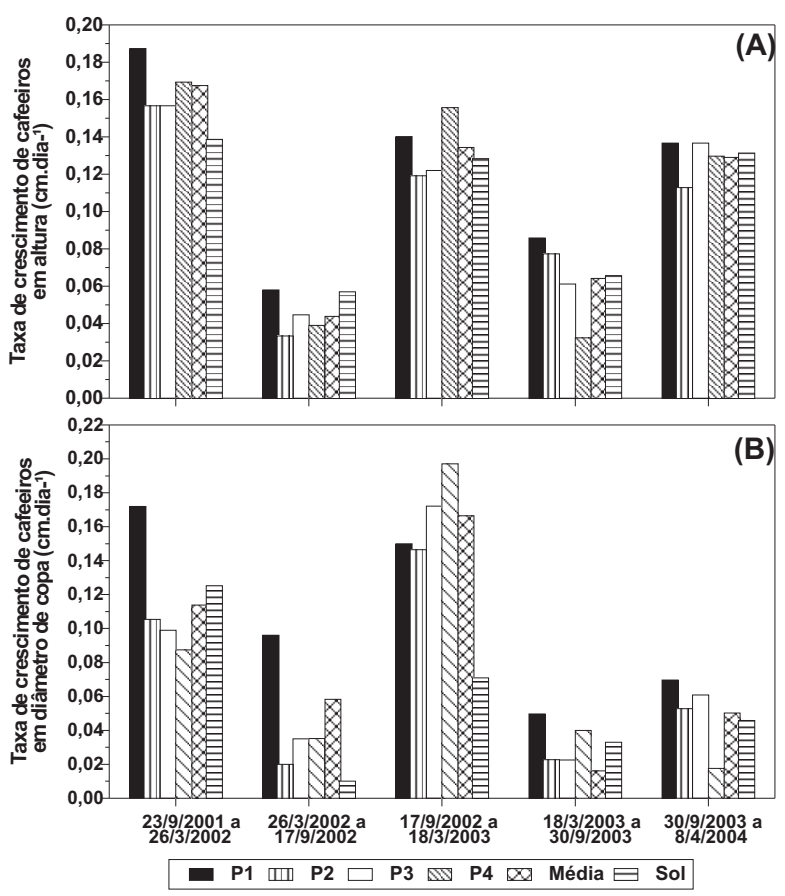

Figura 3. Taxas de crescimento em altura do ramo plagiotrópico (A) e diâmetro máximo da copa (B) de cafeeiros em quatro pontos de amostragem em cultivo consorciado de café com banana 'Prata Anã' (P1 a P4), bem como sua média e em cultivo de café a pleno sol, em cinco períodos, em Mococa (SP).

Ainda com relação à altura dos cafeeiros, não houve diferença entre os padrões sazonais de crescimento em altura entre os pontos amostrais do sistema consorciado e no cultivo a pleno sol. Observando a análise de intervalo de confiança para o crescimento em altura nos cinco períodos de medida (Figura 4A a 4E), pode-se verificar que não houve diferença estatística entre nenhum ponto amostral em qualquer época de medida, embora P1 do sistema consorciado tenha apresentado maiores taxas de crescimento em relação aos outros pontos amostrais no primeiro ano de medidas (Figura 4A e 4B).

Em análise de interceptação da radiação global, Pezzopane et al. (2005), nas condições do experimento em análise, constataram que no P1 do sistema consorciado houve maior interceptação da radiação solar global, o que pode ter influenciado as maiores taxas no primeiro ano de medidas. Quando o sombreamento dos cafeeiros é mais intenso, ocorre 
indução ao maior crescimento em altura, como verificado por Morais et al. (2003). Esses autores, assim como FAHL et al. (1994) e CARELLI et al. (1999) atribuem esse comportamento ao estiolamento, que otimiza a captura de luz.
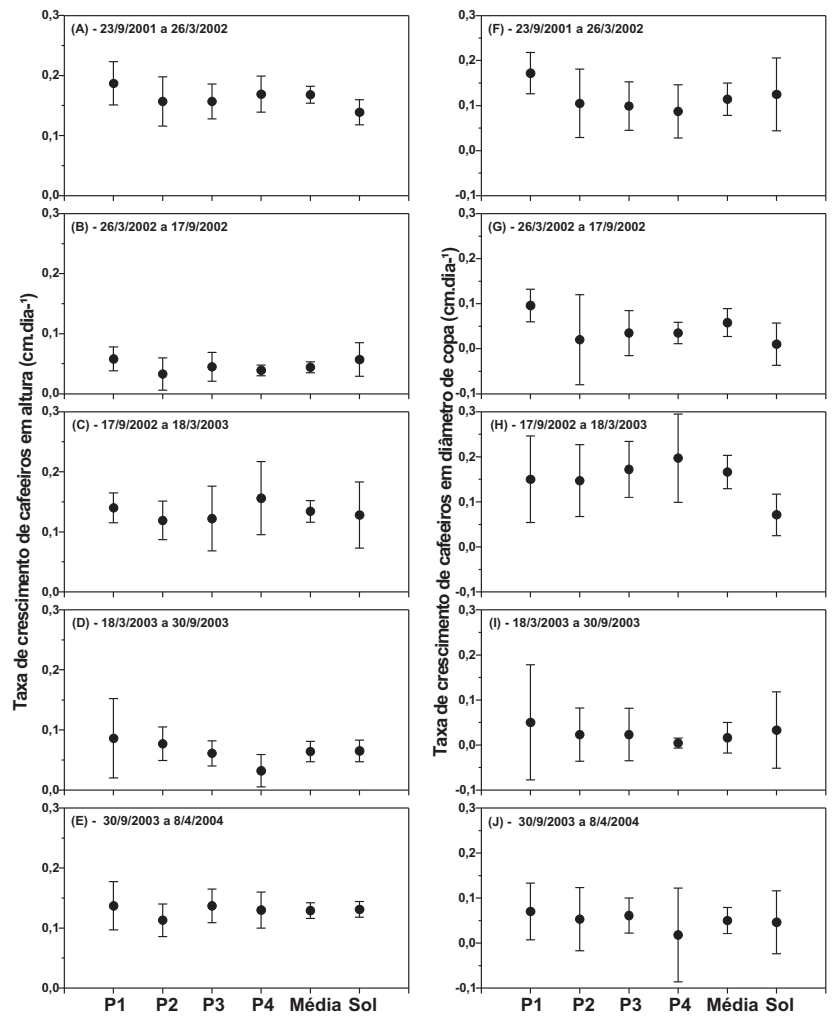

Figura 4. Intervalos de confiança para taxas de crescimento em altura do ramo plagiotrópico (A a E) e diâmetro máximo da copa (F a J) de cafeeiros em quatro pontos de amostragem em cultivo consorciado de café com banana 'Prata Anã' (P1 a P4), bem como sua média e em cultivo de café a pleno sol (Sol), em cinco períodos, em Mococa (SP).

Em relação ao diâmetro da copa (Figura 3B), verificou-se que a variação estacional de seu crescimento foi semelhante à altura nas quatro primeiras medições. Na quinta medição $(30 / 9 / 2003$ a $8 / 4 / 2004)$, embora em se tratando de um período chuvoso, as taxas permaneceram baixas $\left(0,05 \mathrm{~cm} \cdot \mathrm{dia}^{-1}\right.$ em média) para todos os pontos amostrais, provavelmente devido ao crescimento dos ramos plagiotrópicos primários já terem atingido seus valores máximos ou ainda por uma questão da relação fontedreno do cafeeiro, e se tratar de uma época do ano em que estava ocorrendo desenvolvimento dos frutos (Camargo e Pereira, 1994).

Com relação ao comportamento dos diferentes pontos amostrais, verificou-se que no P1 do sistema consorciado as maiores taxas de crescimento em diâmetro no primeiro ano de medições; no segundo período de medidas (Figura 4G), sua taxa foi significativamente maior do que os cafeeiros desenvolvidos a pleno sol. A partir do terceiro período de medições, as plantas de cultivo a pleno sol tiveram as menores taxas de crescimento, e na primaveraverão de 2003, os valores de crescimento em diâmetro diferiram significativamente, pelo critério do intervalo de confiança, em relação à média dos cafeeiros cultivado em consórcio (Figura $4 \mathrm{H}$ ). Para as demais épocas, as taxas de crescimento dos diâmetros da copa não diferiram entre si (Figura 4I e 4J).

\subsection{Desenvolvimento fenológico}

No ano agrícola 2001/2002 (Figura 5A), ao analisar o desenvolvimento fenológico do cultivo de café a pleno sol, verificou-se que no inicio de agosto de 2001, as plantas já estavam na fase de gema entumecida (fase 1), devido à ocorrência de chuvas no fim de julho (Figura 2A). Apesar de se verificar incidência de chuvas no fim de agosto (Figura 2A), não se constatou indução ao florescimento, que só ocorreu no fim de setembro. Após a florada, sucederam-se as fases chumbinho (5) e expansão dos frutos (6), até meado de janeiro, quando foi iniciada a granação (grão verde - 7), até o início da maturação (cereja), que ocorreu no fim de abril. A duração da fase cereja na safra de 2001/2002 teve duração de cerca de 20 dias, período relativamente curto, devido principalmente à ocorrência de elevadas temperaturas em abril e maio de 2002 (Figura 2A).

Ao comparar o desenvolvimento fenológico médio dos cafeeiros do cultivo consorciado e a pleno sol na safra de 2001/2002, só foram verificadas diferenças na mudança de fase de expansão de frutos (6) para grão verde (7), em cerca de 7 dias e na mudança de fase de passa (10) para seco (11), em cerca de 14 dias. Analisando a variabilidade do desenvolvimento fenológico dentro do sistema consorciado, verificouse que P1 diferenciou-se dos demais no estabelecimento da fase gema entumecida (1), com atraso em cerca de 15 dias e na maturação (fases verde cana e cereja) dos frutos, com atraso de 7 dias.

Em relação ao desenvolvimento fenológico do cultivo de café a pleno sol, no ano agrícola 2002/ 2003 (Figura 5B), verifica-se que a ocorrência de chuvas no início de agosto de 2002 (Figura 2A) induziu o desenvolvimento das gemas para a fase de gema entumecida (fase 1) e que a incidência de chuvas mais significativas no fim de agosto (cerca de $40 \mathrm{~mm}$ ) provocou o florescimento dos cafeeiros no início de setembro. No cultivo a pleno sol a sucessão das fases posteriores foi semelhante ao ano anterior, ocorrendo a fase de grão seco no início de junho de 2003. 


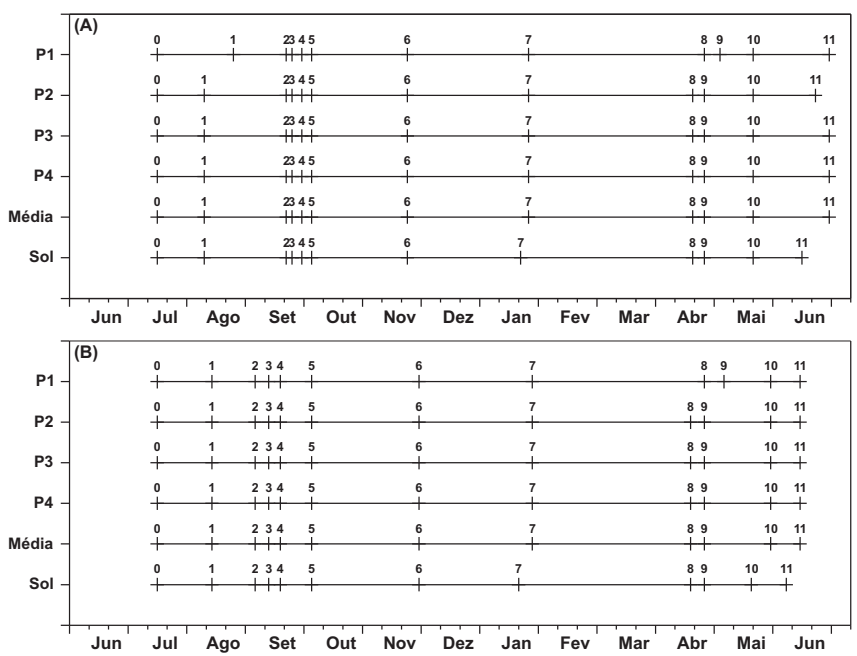

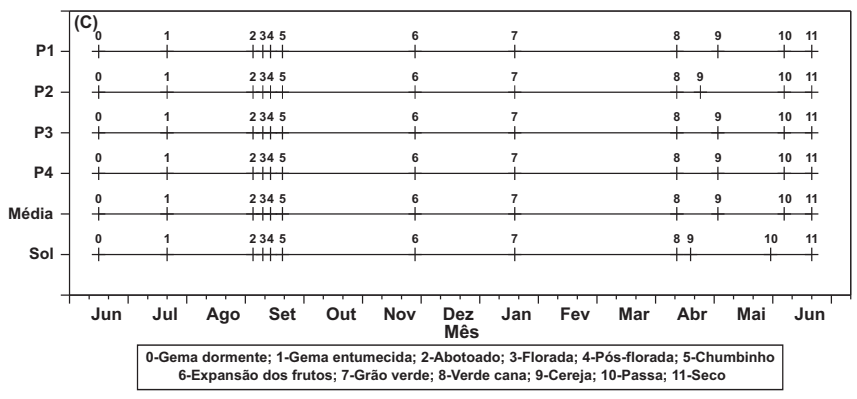

Figura 5. Épocas de ocorrência de estádios fenológicos de cafeeiro, para a florada principal, em quatro pontos de amostragem em cultivo consorciado de café com banana 'Prata Anã' (P1 a P4), bem como sua média e no cultivo de café a pleno sol (Sol) nos anos agrícolas de 2001/2002 (A), 2002/2003 (B) e 2003/2004 (C).

No ano agrícola de 2002/2003 (Figura 5B), verificaram-se diferenças entre os sistemas de cultivo de café a pleno sol e consorciado, na mudança de fase de expansão de frutos (6) para grão verde (7), em cerca de 10 dias e na mudança de fase de cereja (9) para passa (10), em cerca de 10 dias. Com relação à variabilidade do desenvolvimento fenológico dentro do sistema consorciado, P1 diferenciou-se dos demais no estabelecimento da maturação (fases verde cana e cereja) dos frutos, com atraso de 10 dias, assim como no ano anterior.

No ano agrícola de 2003/2004 (Figura 5C), ao analisar o desenvolvimento fenológico do cultivo de café a pleno sol, verificou-se que no mês de julho de 2003, as plantas já estavam na fase de gema entumecida (fase 1), devido à ocorrência de chuvas. O estímulo à florada principal somente ocorreu no fim de agosto, quando foram verificadas chuvas na região (Figura
2A). O florescimento principal se deu no primeiro decêndio de setembro e a sucessão das demais fases culminou com a maturação (cereja) no fim de abril de 2004. A ocorrência de um outono com temperaturas mais baixas que o normal, além da incidência de chuvas em abril e maio, determinou a duração da fase cereja no cultivo a pleno sol em torno de 40 dias.

Quando comparados o desenvolvimento fenológico médio dos cafeeiros do cultivo consorciado e a pleno sol na safra de $2003 / 2004$, foram verificadas diferenças no estabelecimento da maturação (cereja) dos frutos, com atraso de 14 dias no cultivo consorciado a exceção de $\mathrm{P} 2$, onde foi verificado um atraso de 5 dias. A duração da fase cereja no cultivo consorciado foi em torno de 35 dias.

Com relação à maturação dos frutos, ao se analisar os três anos agrícolas, algumas diferenças foram verificadas, como maior duração da fase passa no cultivo consorciado no ano agrícola de 2001/2002, maior duração da fase cereja no cultivo consorciado no ano agrícola de 2002/2003 e maior duração da fase grão-verde no ano agrícola de 2003/2004. Segundo Camargo e Pereira (1994), o maior tempo verificado na maturação dos grãos e na duração da fase cereja, pode se traduzir em uma boa vantagem para o agricultor, permitindo um tempo mais amplo para realizar a colheita seletiva de café cereja.

A variabilidade espacial do desenvolvimento fenológico dentro do sistema consorciado, mostrou em P1 uma demora em atingir a maturação dos frutos nos anos agrícolas de 2001/2002 e 2002/2003, não sendo verificadas diferenças no tempo de maturação entre esse ponto amostral e a maioria dos outros pontos no ano agrícola 2003/2004.

\section{3 Índices de produção}

Índices de produção nos cultivos de café a pleno sol e consorciado com banana 'Prata Anã'

A produção média nos dois sistemas de cultivo não diferiu estatisticamente, pela análise de intervalo de confiança, em nenhuma das três safras,e as colheitas de 2002 e 2004 proporcionaram maiores produções de café da roça (Tabela 1). Nas duas primeiras safras, a produção do sistema a pleno sol superou o sistema consorciado. No entanto, na safra de 2004, quando se observou no sistema consorciado a maior produção dos três anos analisados, sendo superior em cerca de $20 \%$ à do cultivo a pleno sol.

De certa maneira a competição entre o crescimento vegetativo e o processo de produção (CAMARgo e CAMARGo, 2001), pode explicar maiores 
taxas de crescimento em altura e diâmetro no cultivo consorciado (Figura $4 \mathrm{~A}, 4 \mathrm{C}$ e $4 \mathrm{H}$ ) e menores produções nos dois primeiros anos analisados para esse cultivo, em relação ao pleno sol.

$\mathrm{Na}$ safra de 2003 foram obtidas as menores produções para os dois sistemas de cultivo. Um dos fatores que afetaram a produção de café em 2003 foi a seca ocorrida na região em 2002 (Figura 2B), que prejudicou desde a diferenciação das gemas, no início de março, até o início da expansão dos frutos, em novembro.

A grande variabilidade dos dados de produção das parcelas, com elevados valores de intervalo de confiança, principalmente em 2002, pode ser atribuída ao fato de ter sido o primeiro ano de produção das lavouras.

Em trabalhos realizados com sistemas de produção de café em consórcio na região sudeste do
Brasil, Neves et al. (2001) e LimA et al. (2003) também não observaram diferenças entre as produções de sistema consorciado de produção de café com banana e a pleno sol nas primeiras produções, apesar da grande variabilidade dos dados verificados por esses autores.

Ao analisar os valores médios das três safras relacionados ao rendimento, também não foram encontradas diferenças significativas entre os dois sistemas de produção. Em 2003 e 2004, os valores médios do sistema a pleno sol foram maiores que o consorciado (43,6\% e $44,6 \%$ no cultivo a pleno sol e $41,3 \%$ e $41,9 \%$ no consorciado respectivamente). Observando os dados obtidos desse parâmetro nas três safras, pode-se verificar em 2003 as maiores diferenças entre os sistemas, embora a baixa produção das parcelas nessa safra tenha provocado grande variabilidade dos dados apresentados, ocorrendo os maiores valores de intervalo de confiança, principalmente no sistema consorciado.

Tabela 1. Produção de café ( $\mathrm{kg}$ de café da roça $/ 340 \mathrm{~m}^{2}$ ) e rendimento (\%) em cultivo de café a pleno sol (PS) e consorciado com banana 'Prata Anã' (CONS) nos anos de 2002, 2003 e 2004, em Mococa (SP)

\begin{tabular}{|c|c|c|c|c|c|c|c|c|c|}
\hline \multirow{3}{*}{ Parâmetros } & & \multicolumn{8}{|c|}{ Ano } \\
\hline & & \multicolumn{2}{|c|}{2002} & \multicolumn{2}{|c|}{2003} & \multicolumn{2}{|c|}{2004} & \multicolumn{2}{|c|}{ 2002-2004 } \\
\hline & & PS & Cons & PS & Cons & PS & Cons & PS & Cons \\
\hline Produção (kg) & $\begin{array}{c}\text { Média } \\
\text { DP }\end{array}$ & $\begin{array}{l}92,9 \mathrm{a} \\
31,3\end{array}$ & $\begin{array}{l}83,7 \text { a } \\
30,2\end{array}$ & $\begin{array}{l}17,1 \text { a } \\
14,4\end{array}$ & $\begin{array}{c}10,2 \mathrm{a} \\
6,2\end{array}$ & $\begin{array}{c}84,6 \text { a } \\
7,9\end{array}$ & $\begin{array}{c}102,7 \text { a } \\
23,4\end{array}$ & $\begin{array}{c}194,6 \mathrm{a} \\
25,7\end{array}$ & $\begin{array}{c}196,6 \text { a } \\
51,8\end{array}$ \\
\hline Rendimento (\%) & $\begin{array}{l}\text { Média } \\
\text { DP }\end{array}$ & $\begin{array}{c}45,6 \mathrm{a} \\
3,2\end{array}$ & $\begin{array}{c}45,8 \mathrm{a} \\
2,7\end{array}$ & $\begin{array}{c}43,6 \mathrm{a} \\
3,0\end{array}$ & $\begin{array}{c}41,3 \mathrm{a} \\
4,4\end{array}$ & $\begin{array}{c}44,6 \mathrm{a} \\
3,0\end{array}$ & $\begin{array}{c}41,9 \mathrm{a} \\
1,1\end{array}$ & $\begin{array}{c}44,6 \mathrm{a} \\
2,8\end{array}$ & $\begin{array}{c}43,0 \mathrm{a} \\
2,4\end{array}$ \\
\hline
\end{tabular}

Médias seguidas de mesma letra na horizontal no mesmo ano, não diferem entre si ao nível de 5\% pela análise de intervalo de confiança.

\subsection{Variabilidade espacial dos índices de produção no cultivo de café consorciado com banana 'Prata Anã'}

Na produção dos pontos amostrais dentro do sistema consorciado, foi observada diferença estatística, na colheita realizada em 2002, pelo teste de Tukey, entre P1 (situado mais próximo à bananeira) e os outros pontos amostrais do sistema consorciado (Tabela 2). Nos outros anos não se observou diferença estatística, devido aos altos valores de coeficiente de variação, embora P1 tivesse menor valor de produção, principalmente em 2004, quando foram obtidas as maiores produções de café beneficiado por planta durante os três anos.

Ao analisar o total de produção das três safras, verificou-se diferença estatística entre P1 e P2 (situado entre duas bananeiras), com menor valor de produção para $\mathrm{P} 1$. Os pontos situados na rua intercalar de café entre as ruas de bananeiras (P3 e P4) não diferiram entre si e também em relação aos outros pontos.

Para o rendimento, embora tenha sido verificada diferença estatística na safra de 2002, com maior valor $(51,2 \%)$ para P1 em relação a P3 e P4 (43,2 e 43,7\% respectivamente), ao analisar os dados médios das três safras não foram encontradas diferenças estatísticas entre os pontos amostrais. Apesar disso, observou-se o maior valor médio de rendimento $(48,4 \%)$ em P1, enquanto em outros pontos amostrais o rendimento médio foi cerca de $45 \%$.

Para os dois índices analisados, de maneira geral, verificou-se que P1 diferenciou-se dos demais. Confrontando-se os dados de produção das plantas com o crescimento vegetativo em altura e diâmetro, repetiu-se a tendência apresentada na comparação entre os sistemas de produção. No primeiro ano, P1 foi o que apresentou, no sistema consorciado, as maiores taxas de crescimento em altura e diâmetro (Figura 4A e 4F), dando menor produção (Tabela 2), fato que voltou a se repetir no terceiro ano (Figura $4 \mathrm{E}$ e 4J)., concordando com CANNELL (1976), assim como DAMAтTA (2004), onde relatam que em condição de sombreamento excessivo, as plantas de café tendem apresentar menores produções devido ao maior estímulo à emissão de gemas vegetativas em detrimento das gemas florais e a menor emissão de nós, responsáveis diretos pela produção. 
Tabela 2. Produção de café (kg de café beneficiado/planta) e rendimento (\%) em quatro pontos amostrais no cultivo de café consorciado com banana 'Prata Anã' (P1, P2, P3 e P4) em 2002, 2003 e 2004, em Mococa (SP)

\begin{tabular}{lcccc}
\hline $\begin{array}{l}\text { Tratamento/ } \\
\text { Ano }\end{array}$ & 2002 & 2003 & 2004 & $2002-2004$ \\
\hline \multicolumn{5}{c}{ Produção (kg de café beneficiado/planta) } \\
P1 & $0,114 \mathrm{~b}$ & 0,079 & 0,624 & $0,818 \mathrm{~b}$ \\
P2 & $0,353 \mathrm{a}$ & 0,078 & 0,990 & $1,421 \mathrm{a}$ \\
P3 & $0,321 \mathrm{a}$ & 0,073 & 0,649 & $1,043 \mathrm{ab}$ \\
P4 & $0,333 \mathrm{a}$ & 0,065 & 0,703 & $1,101 \mathrm{ab}$ \\
F & $11,74^{* *}$ & $0,29 \mathrm{~ns}$ & $1,95 \mathrm{~ns}$ & $4,08 *$ \\
\hline C.V. (\%) & 32,91 & 46,37 & 46,18 & 31,77 \\
\hline \multicolumn{5}{c}{ Rendimento $(\%)$} \\
P1 & $51,2 \mathrm{a}$ & 45,1 & 48,8 & 48,4 \\
P2 & $44,7 \mathrm{ab}$ & 42,6 & 48,5 & 45,3 \\
P3 & $43,2 \mathrm{~b}$ & 46,2 & 48,4 & 45,9 \\
P4 & $43,7 \mathrm{~b}$ & 45,4 & 46,4 & 45,1 \\
F & $4,39^{*}$ & $0,69 \mathrm{~ns}$ & $0,92 \mathrm{~ns}$ & $2,71 \mathrm{~ns}$ \\
\hline C.V. (\%) & 11,05 & 11,74 & 6,86 & 5,60 \\
\hline
\end{tabular}

Médias seguidas pela mesma letra, na vertical, não diferem entre si, pelo teste de Tukey a $5 \%$.

**; *: Significativo ao nível de $1 \%$ e de $5 \%$ respectivamente. ns: Não Significativo.

\section{CONCLUSÕES}

1. Nos sistemas de cultivo avaliados, o crescimento vegetativo, em altura e diâmetro da copa, apresentou maior atividade no período primaveraverão em relação ao período outono-inverno, não tendo sido observadas diferenças significativas das taxas de crescimento, do desenvolvimento fenológico e dos índices de produção.

2. No cultivo consorciado, em cafeeiros próximos às bananeiras, verificaram-se diferenças no crescimento vegetativo e desenvolvimento fenológico para algumas épocas do ano em relação aos demais pontos amostrados, além de menor produção por planta.

\section{AGRADECIMENTOS}

Ao CNPq e à Fapesp, pelas bolsas concedidas aos autores e ao Consórcio Brasileiro de Pesquisa e Desenvolvimento do Café, pelo apoio financeiro.

\section{REFERÊNCIAS}

BARROS, R.S.; MAESTRI, M. Influência dos fatores climáticos sobre a periodicidade de crescimento vegetativo do café (Coffea arabica L.). Revista Ceres, Viçosa, v. 21, p. 268-279, 1974.
BEER, J.; MUSCHLER, R.; KASS, D.; SOMARRIBA, E. Shade management in coffee and cacao plantations. Agroforestry Systems, Amsterdam, v. 38, p. 139-164, 1998.

CAMARGO, A. P. A arborização como meio de reduzir as adversidades climáticas e promover a sustentação da agricultura. In: CONGRESSO BRASILEIRO DE PESQUISAS CAFEEIRAS, 16., Espirito Santo do Pinhal, 1990. Trabalhos apresentados... Rio de Janeiro: IBC, 1990. p.6-7.

CAMARGO, A.P.; PEREIRA, A.R. Agrometeorology of the coffee crop. World Meteorological Organization. Geneva: WMO/TD, 1994. n. 615, 43 p.

CAMARGO, M.B.P.; CAMARGO, A.P. Representação gráfica informatizada do extrato do balanço hídrico de Thornthwaite \& Mather. Bragantia, Campinas, v.52, n.2, p.169 - 172, 1993.

CAMARGO, A.P.; CAMARGO, M.B.P. Definição e esquematização das fases fenológicas do cafeeiro arábica nas condições tropicais do Brasil. Bragantia, Campinas, v. 60, n. 1, p. $65-68,2001$

CANNELL, M.G.R. Crop physiological aspects of coffee bean yield : a review. Kenya Coffee, Nairobi, v. 41, p. 245-253, 1976.

CARELLI, M.L.C.; FAHL, J.I.; TRIVELIN, P.C.O.; QUEIROZVOLTAN, R.B. Carbon isotope discrimination and gas exchange in Coffee species grown under different irradiance regimes. Revista Brasileira de Fisiologia Vegetal, v. 11, n. 2, p.63-68, 1999.

DAMATTA, F.M. Ecophysiological constraints on the production of shaded and unshaded coffee: a review. Field Crops Research, Amsterdam, v. 86, p. 99-114, 2004.

EMPRESA BRASILEIRA DE PESQUISA AGROPECUÁRIA. Sistema Brasileiro de classificação de solos. Brasília: Centro Nacional de Pesquisa de Solos, 1999. 412 p.

FAHL, J.I.; CARELLI, M.L.C.; VEGA, J; MAGALHÃES, A.C. Nitrigen and irradiance affecting net photosynthesis and growth of young coffee plants (Coffea arabica L.) Journal of Horticultural Science, Ashford, v. 69, p. 161-169, 1994.

LIMA, P.C.; MOURA, W.M.; PEREIRA, A.A.; RIBEIRO, P.M. Unidades experimentais de cafeeiros sob sistema de produção orgânica no município de Heliodora, Minas Gerais. In: SIMPÓSIO DE PESQUISAS DOS CAFÉS DO BRASIL, 3., Porto Seguro, 2003. Anais... Brasília: EMBRAPA Café, 2003. p.438-439.

MATIELLO, J.B.; SANTINATO, R.; GARCIA, A.W.R.; ALMEIDA, S.R.; FERNANDES, D.R. Cultura de Café no Brasil: Novo Manual de Recomendações. Rio de Janeiro: MAPA/ PROCAFE, 2002. 388p.

MORAIS, H.; MARUR, C.J.; CARAMORI, P.H.; RIBEIRO, A.M.A.; GOMES, J.C. Características fisiológicas e de crescimento de cafeeiro sombreado com guandu e cultivado a pleno sol. Pesquisa Agropecuária Brasileira, Brasília, v. 38, n. 10, p. 1131-1137, 2003. 
NEVES, Y.P.; MARTINEZ, H.E.P.; SOUZA, C.M.; CECON, P.R. Crescimento e produção de Coffea arabica, fertilidade do solo e retenção de umidade em sistema agroflorestal. In: SIMPÓSIO DE PESQUISAS DOS CAFÉS DO BRASIL, 2., Vitória, 2001. Resumo Expandidos... Brasília: EMBRAPA Café, 2001. p. 1678-1686.

PEZZOPANE, J.R.M., PEDRO JÚNIOR, M.J., THOMAZIELLO, R.A., CAMARGO, M.B.P. Escala para avaliação de estádios fenológicos do cafeeiro Arábica. Bragantia, Campinas, v. 62, n.3, p.499-505, 2003.
PEZZOPANE, J.R.M., PEDRO JÚNIOR, M.J.; GALLO, P.B. Radiação solar e saldo de radiação em cultivo de café a pleno sol e consorciado com banana 'Prata Anã'. Bragantia, v.64, p.487- 499, 2005.

VAAST, P., KANTEN, R.V., SILES, P., DZIB, B., FRANCK, N., HARMAN, J.M, GENARD, M. Shade: A key factor for coffee sustainability and quality. In: ASIC CONFERENCE, Bangalore, India, 2004. CD-ROOM. 